\section{New cholesterol targets for patients at high or very high cardiovascular risk and the indications for PCSK9 inhilhitors}

To the Editor: Proprotein convertase subtilisin/kexin type 9 (PCSK9) inhibitors are members of a new class of lipid-lowering drugs that reduce low-density lipoprotein cholesterol (LDL-C) levels on average by $60 \%$ when administered alone or when added to maximally tolerated statin therapy with or without ezetimibe. There is a consistent relationship between lower achieved LDL-C and the absolute LDL-C reduction (determined by pretreatment LDL-C levels and the LDL-lowering efficacy of the medications), and lower risk of cardiovascular events, which is significant within the first year of treatment. ${ }^{[1-8]}$ Sub-analysis of an international study has demonstrated that the benefit of PCSK9 inhibitors in South African (SA) patients with familial hypercholesterolaemia (FH) is comparable to that observed in the rest of the world. ${ }^{[9]}$

In 2018 we published an update of the South African Dyslipidaemia Guideline Consensus Statement from the South African Heart Association (SA Heart) and the Lipid and Atherosclerosis Society of Southern Africa (LASSA) in which we described LDL-C targets and recommendations for the use of PCSK9 inhibitors in patients at high or very high risk of atherosclerotic cardiovascular disease (ASCVD) events. ${ }^{[10]}$ At the time of publication, PCSK9 inhibitors were not yet commercially available in SA. SA Heart and LASSA are aligned with the European Society of Cardiology (ESC)/European Society of Atherosclerosis (EAS), and our recommendations were based on those in the 2016 European guidelines. ${ }^{[11]}$

The ESC/EAS Guideline has recently been updated with lower cholesterol targets for patients at high or very high ASCVD risk, ${ }^{[12]}$ and these are different from those recommended in the 2018 SA guideline. ${ }^{[10]}$ Consequently, we recommend that SA clinicians note the revised LDL-C targets and factor these into their therapeutic decision-making, as PCSK9 inhibitors are now registered for use in SA and available for our patients.

The new recommendations and revised concepts are: ${ }^{[12]}$

1. For patients at very high risk, both for primary prevention and secondary prevention, an LDL-C reduction of $\geq 50 \%$ from baseline and an LDL-C goal of $<1.4 \mathrm{mmol} / \mathrm{L}$ are recommended. An LDL-C goal of $<1.0 \mathrm{mmol} / \mathrm{L}$ may be considered for patients who experience a second atherosclerotic vascular event within 2 years (not necessarily the same type as the first event) while taking maximally tolerated statin therapy.

2. For patients with type 2 diabetes mellitus (T2DM) at very high risk, an LDL-C reduction of $\geq 50 \%$ from baseline and an LDL-C goal of $<1.4 \mathrm{mmol} / \mathrm{L}$ are recommended. In patients with T2DM at high risk, an LDL-C reduction of $\geq 50 \%$ from baseline and an LDL-C goal of $<1.8 \mathrm{mmol} / \mathrm{L}$ are recommended.

3. For patients at high risk, an LDL-C reduction of $\geq 50 \%$ from baseline and an LDL-C goal of $<1.8 \mathrm{mmol} / \mathrm{L}$ are recommended.

4. Targets for patients at moderate and low risk remain $<2.6 \mathrm{mmol} / \mathrm{L}$ and $<3.0 \mathrm{mmol} / \mathrm{L}$, respectively.

5. For patients who present with an acute coronary syndrome (ACS), and whose LDL-C levels are not at goal despite already taking a maximally tolerated statin dose and ezetimibe, adding a PCSK9 inhibitor early after the event (if possible during hospitalisation for the ACS event) should be considered. If the LDL-C goal is not achieved after 4 - 6 weeks in prior lipid-lowering therapy-naive patients, despite maximal tolerated statin therapy and ezetimibe, addition of a PCSK9 inhibitor is recommended.
6. For secondary prevention patients at very high risk not achieving their goal on a maximum tolerated dose of statin and ezetimibe, a combination with a PCSK9 inhibitor is recommended.

7. In primary prevention for individuals with heterozygous $\mathrm{FH}$ at very high risk, an LDL-C reduction of $\geq 50 \%$ from baseline and an LDL-C goal of $<1.4 \mathrm{mmol} / \mathrm{L}$ should be considered. Treatment with a PCSK9 inhibitor is recommended for very high-risk FH patients if the treatment goal is not achieved on maximal tolerated statin plus ezetimibe. For very high-risk FH patients (i.e. with ASCVD or with another major risk factor) who do not achieve their goals on a maximum tolerated dose of statin and ezetimibe, a combination with a PCSK9 inhibitor is recommended.

Readers are referred to Table 4 of the 2019 ESC/EAS Guideline ${ }^{[12]}$ for criteria defining cardiovascular risk categories. The SA Dyslipidaemia Guideline Consensus Statement is available to download (http:// www.samj.org.za/index.php/samj/article/view/12479).

\section{E Q Klug}

Cardiologist, Netcare Sunninghill and Sunward Park hospitals, Gauteng Province, South Africa; Associate Professor, School of Clinical Medicine, Faculty of Health Sciences, University of the Witwatersrand, Johannesburg, South Africa; and Division of Cardiology, Charlotte Maxeke Johannesburg Academic Hospital, South Africa drklug@tickerdoc.co.za

\section{F J Raal}

Director, Carbohydrate and Lipid Metabolism Research Unit, University of the Witwatersrand, Johannesburg, South Africa; and Professor and Head, Division of Endocrinology and Metabolism, Faculty of Health Sciences, University of the Witwatersrand, Johannesburg, South Africa

frederick.raal@wits.ac.za

1. Giugliano RP, Pedersen TR, Park JG, et al. Clinical efficacy and safety of achieving very low LDL cholesterol concentrations with the PCSK9 inhibitor evolocumab: A prespecified secondary analysis of the FOURIER trial. Lancet 2017;390(10106):1962-1971. https://doi.org/10.1016/S0140-6736(17)32290-0 2. Sabatine MS, Giugliano RP, et al. Efficacy and safety of evolocumab in reducing lipids and cardiovascular events. N Engl J Med 2015;727:1500-1509. https://doi.org/10.1056/NEJMoa1500858

3. Bonaca MP, Nault P, Giugliano RP, et al. Low-density lipoprotein cholesterol lowering with evolocumab and outcomes in patients with peripheral artery disease: Insights from the FOURIER Trial (Further Cardiovascular Outcomes Research With PCSK9 Inhibition in Subjects With Elevated Risk). Circulation 2018;137(4):338-350. https://doi.org/10.1161/CIRCULATIONAHA.117.032235

4. Sabatine MC, Leiter LA, Wiviott SD, et al. Cardiovascular safety and efficacy of the PCSK9 inhibito evolocumab in patients with and without diabetes and the effect of evolocumab on glycaemia and risk of new-onset diabetes: A prespecified analysis of the FOURIER randomised controlled trial. Lancet 2017;5(12):941-950. https://doi.org/10.1016/S2213-8587(17)30313-3

Robinson J, Farnier M, Krempf M, et al. Efficacy and safety of alirocumab in reducing lipids and cardiovascular events. N Engl J Med 2015;372:1489-1499. https://doi.org/10.1056/NEJMoal50103

Kereiakes D, Robinson J, Cannon C, et al. Efficacy and safety of the proprotein convertase subtilisin/ kexin type 9 inhibitor alirocumab among high cardiovascular risk patients on maximally tolerated statin therapy: The ODYSSEY COMBO I study. Am Heart J 2015;169(6):906-915. https://doi.org/10.1016/j. ahj.2015.03.004

7. Kastelein J, Ginsberg H, Langslet G, et al. ODYSSEY FH I and FH II: 78 week results with alirocumab treatment in 735 patients with heterozygous familial hypercholesterolaemia. Eur Heart J 2015;36(43):2996-3003. https://doi.org/10.1093/eurhearti/ehv370

8. Ginsburg HN, Rader DJ, Raal FJ, et al. Efficacy and safety of alirocumab in patients with heterozygous . Ginsburg HN, Rader DJ, Raal FJ, et al. Efficacy and safety of alirocumab in patients with heterozygous
familial hypercholesterolemia and LDL-C of $160 \mathrm{mg} /$ dl or higher. Cardiovasc Drugs Ther 2016;30(5):473familial hypercholesterolemia and LDL-C of 160

9. Blom DI, Breedt J, Burgess LJ, et al. Long-term safety and efficacy of alirocumab in South African Blom DJ, Breedt J, Burgess LJ, et al. Long-term safety and efficacy of alirocumab in South African
patients with heterozygous familial hypercholesterolaemia: The ODYSSEY Open-Label Extension study patients with heterozygous familial hypercholesterolaemia: The ODYSSEY Op

10. Klug EQ, Raal FJ, Marais AD, et al. South African Dyslipidaemia Guideline Consensus Statement: A join Klug EQ, Raal F,, Marais AD, et al. South African Dyslipidaemia Guideline Consensus Statement: A join
statement from the South African Heart Association (SA Heart) and the Lipid and Atherosclerosis statement from the South African Heart Association (SA Heart) and the Lipid and Atherosclerosis
Society of South Africa (LASSA). S Afr Med J 2018;108(11, Pt 2): 973-1000. https://doi.org/10.7196/ SAMJ.2018.v108i11.13383

11. Catapano AL, Graham I, de Backer G, et al.; ESC Scientific Document Group. 2016 ESC/EAS Guidelines for the Management of Dyslipidaemias. Eur Heart J 2016;37(39):2999-3058. https://doi.org/10.1093 eurheartj/ehw272

12. Mach F, Baigent C, Catapano AL, et al.; ESC Scientific Document Group. 2019 ESC/EAS Guidelines fo the management of dyslipidaemias: Lipid modification to reduce cardiovascular risk: The Task Force for the management of dyslipidaemias of the European Society of Cardiology (ESC) and European Atherosclerosis Society (EAS). Eur Heart J 2020;41(1):111-188. https://doi.org/10.1093/eurhearti/ehz45

S Afr Med J 2020;110(11):1059. https://doi.org/10.7196/SAMJ.2020.v110i11.15191 